\section{Elderly with refractory chronic severe hyponatremia and anesthesia management dilemma: a case report with literature review}

\author{
Manish Keshwani, ${ }^{1}$ \\ Habib Md Reazaul Karim, ${ }^{1}$ \\ Suresh Nagalikar, ${ }^{1}$ \\ Deepak Kumar Biswal, ${ }^{2}$ Samarjit Dey ${ }^{1}$ \\ ${ }^{1}$ Department of Anaesthesiology, Critical \\ Care and Pain Medicine, All India \\ Institute of Medical Sciences Raipur, \\ India; ${ }^{2}$ Department of Urology, All India \\ Institute of Medical Sciences Raipur, \\ India
}

\begin{abstract}
Hyponatremia is a common electrolyte disorder, especially in the frail elderly population. With the increasing number of surgeries in the aging population, hyponatremia is frequently encountered by anesthesiologists and surgeons. Unfortunately, management of hyponatremia is often complex in the elderly population as it is often multifactorial, and they are physiologically susceptible. While it is well known that preoperative hyponatremia is associated with increased perioperative morbidity and mortality, a lack of recommendations or guidelines adds to the dilemma in managing such cases. The most common cause of chronic hyponatremia in the elderly is the syndrome of inappropriate antidiuretic hormone (SIADH), which can be resistant to conventional treatment.

On the other hand, paraneoplastic SIADH leading to hyponatremia is rare, and surgery may be the only option available for its correction. We present a case of a 78years-gentleman to highlight such a dilemma. He was diagnosed with renal cell carcinoma and had chronic refractory severe hyponatremia despite treatment with fluid restriction, low dose hydrocortisone, tolvaptan, and 3\% sodium chloride.
\end{abstract}

\section{Introduction}

Serum electrolytes estimation as a part of the preoperative investigation is required chiefly for major urological surgeries. A serum $\mathrm{Na}+$ concentration of $<135 \mathrm{meq} / \mathrm{L}$ is defined as hyponatremia. ${ }^{1}$ Age is a strong independent risk factor for hyponatremia, and elderly patients represent a high-risk group. ${ }^{2}$ Dysnatraemia affects the central nervous system or cardiovascular system's function and is associated with significant postoperative morbidity and mortality. ${ }^{3}$ Although routine preoperative testing in the elderly is not beneficial, ${ }^{4,5}$ indicated that preoperative laboratory testing in the elderly helps predict postoperative adverse events. ${ }^{6}$ Despite the fact that hyponatremia occurs in nearly $14 \%$ of the elderly in clinical practice, ${ }^{7}$ literature regarding the management of major surgery with refractory hyponatremia is sparse. We present case management of elderly gentlemen with chronic severe refractory hyponatremia posted for laparoscopic nephrectomy.

\section{Case Report}

A 78-years-old gentleman weighing 50 $\mathrm{kg}$ came to the urology outpatient department with the complaint of fever for one month and mild hematuria. Work-up revealed a right renal mass for which laparoscopic nephrectomy was planned. He is a known case of diabetes mellitus and hypertension for the past 30 years and is on oral hypoglycemics and calcium channel blockers. He is also having a diabetic ulcer over his right foot. On arrival, his blood sugar was $168 \mathrm{mg} / \mathrm{dL}$, blood urea 52 $\mathrm{mg} / \mathrm{dL}$, serum creatinine was $1.1 \mathrm{mg} / \mathrm{dL}$ with estimated glomerular filtration rate $39.14 \mathrm{~mL} / \mathrm{min} / 1.73 \mathrm{~m}^{2}$, serum sodium 125 $\mathrm{meq} / \mathrm{L}$ and hemoglobin $10 \mathrm{gm} / \mathrm{dL}$. He was evaluated for hyponatremia; an endocrinologist consultation was obtained. His thyroid-stimulating hormone and cortisol level was normal; calculated serum osmolarity was $269 \mathrm{mOsmol} / \mathrm{kg}$. Urine osmolality could not be done due to logistic issues, but specific gravity was normal. His serum sodium level did not improve even after fluid restriction, Tolvaptan treatment for six days, low-dose hydrocortisone, and even with $3 \%$ sodium chloride of $20 \mathrm{~mL} / \mathrm{h}$ for three days. However, no hyponatremiarelated symptoms and signs were present during the preoperative period.

As the case needed to be expedited, the patient was taken for surgery with risk explained for severe hyponatremia. General anesthesia was induced with injection propofol and fentanyl and maintained on desflurane. Tracheal intubation was facilitated by injection vecuronium. Hemodynamically, the patient was stable intraoperatively. Therefore, only normal saline was used as the intraoperative and immediate postoperative fluid. Ultrasoundguided right quadrates lumborum block was
Correspondence: Habib Md Reazaul Karim, Faculty Room A001, Block A, AIIMS Raipur Hospital Complex, GE Road, Tatibandh,

Raipur, PIN-492099 India.

E-mail: drhabibkarim@gmail.com

Key words: Hyponatremia; elderly; paraneoplastic syndrome; syndrome of inappropriate antidiuretic hormone.

Contributions: MK, HMRK, SN, DKB, SD, case management, manuscript preparation, literature search; HMRK, editing; MK, DKB, manuscript revision.

Conflict of interest: the authors declare no potential conflict of interest.

Ethical statement and consent: informed written consent was obtained from the patient for publishing the report. In our institute, a case report does not require ethical approval.

Received for publication: 15 June 2021

Revision received: 28 September 2021.

Accepted for publication: 8 November 2021.

This work is licensed under a Creative

Commons Attribution-NonCommercial 4.0

International License (CC BY-NC 4.0).

${ }^{\circ}$ Copyright: the Author(s), 2021

Licensee PAGEPress, Italy

Geriatric Care 2021; 7:9911

doi:10.4081/gc.2021.9911

performed before extubating the patient. His visual analog scores for pain remained $<4 / 10$ for the first $24 \mathrm{~h}$ and serum sodium $127 \mathrm{meq} / \mathrm{L}$ on the first postoperative day. Paracetamol was used as a rescue analgesic for the next two days and his serum sodium improved to $136 \mathrm{meq} / \mathrm{L}$ over the next $72 \mathrm{~h}$. No complication was noted, and the gentleman was discharged home.

\section{Discussion and Conclusions}

The present case highlights a frequently encountered clinical dilemma in perioperative patients. As the numbers of aged populations increase and older adults often need anesthesia services for multiple illnesses and comorbidities, more such patients will be encountered in the coming days. Therefore, it has become essential to focus on the perioperative management of chronic hyponatremia in elderly patients.

The Elderly are more prone to develop hyponatremia due to impaired renal water excretion, decreased glomerular filtration, comorbidities often requiring polypharmacy related to hyponatremia. ${ }^{2,8}$ Even rare 
idiopathic syndrome of inappropriate antidiuretic hormone secretion (SIADH) is more frequently observed in the elderly. ${ }^{9}$ Our patient was on a calcium channel blocker and Insulin. Persistent hyponatremia, even after blood sugar was controlled, ruled out pseudo hyponatremia. SIADH can be diagnosed with decreased blood osmolality $(<280 \mathrm{mOsm} / \mathrm{kg})$ with inappropriately increased urine osmolality (>150 $\mathrm{mOsm} / \mathrm{kg}$ ); normal thyroid and adrenal function along with urine sodium usually over $20 \mathrm{meq} / \mathrm{L}$. Normal urine specific gravity, absence of heart failure, and cirrhosis pointed towards our patient's possible differential diagnosis of SIADH, reset osmostat syndrome, and renal salt wasting. Malignancy can be associated with hyponatremia due to poor diet, adrenal dysfunction, renal or cerebral salt wasting, and SIADH via ectopic arginine vasopressin (AVP) production or chemotherapy-induced AVP stimulation. ${ }^{10}$ Further, paraneoplastic syndrome is a crucial aspect to consider. The tumors most commonly resulting in hyponatremia of the SIADH type are lung, breast, and head and neck tumors. ${ }^{11}$ Although hyponatremia is reported in patients with localized renal cell carcinoma, a serum sodium level of $\leq 125$ is rarely reported. ${ }^{12}$

The prevalence of chronic hyponatremia is dependent on the level of serum sodium used to define the disorder and the setting in which the measurement is made. Caird et al. noted that approximately $7 \%$ of patients aged $>65$ years had serum sodium concentrations $<137 \mathrm{mEq} / \mathrm{L} .{ }^{13}$ When a serum sodium concentration $<135 \mathrm{mEq} / \mathrm{L}$ is used as a cutoff, it is $20 \%$ among long-term care facility residents. ${ }^{14}$

There is often a mismatch between the severity of the symptoms and the degree of hyponatremia partly because the speed of onset of hyponatremia is of greater prognostic significance than the degree of hyponatremia itself. ${ }^{15}$ Many patients with long-standing hyponatremia may appear to be clinically asymptomatic. However, even in these asymptomatic patients, laboratory studies indicate that cell functions are affected. ${ }^{16,17}$ Low sodium concentration should be corrected even in asymptomatic elderly individuals because it is related to increased mortality and morbidity. ${ }^{18,19}$ In acute symptomatic hyponatremia, hypertonic saline solution (3\%) is commonly used to increase serum sodium levels acutely. Hypertonic saline is usually not indicated in chronic, mild, asymptomatic hyponatremia, but profound hyponatremia $(\mathrm{Na}+$ $125 \mathrm{meq} / \mathrm{L})$ needs aggressive therapy with or without vasopressin receptor antagonists. ${ }^{20}$ Interestingly, even after a tar- get of $7 \mathrm{meq} / \mathrm{L}$ corrections per day for three days, his serum $\mathrm{Na}+$ level did not improve. Hypovolemic hyponatremia is treated with adequate fluid resuscitation with normal saline to suppress the hypovolemic stimulus for ADH release. ${ }^{21}$ In patients with SIADH and discontinued suspected drugs and decreased water consumption, careful administration of hypertonic fluids may be needed. Other options are vaptans (vasopressin-2 antagonists) that selectively antagonize the antidiuretic effect of vasopressin, leading to increased water diuresis used in hospitalized patients with chronic symptomatic euvolemic hyponatremia. ${ }^{22}$ Administration of low-dose hydrocortisone $(10 \mathrm{mg} /$ day or less) can be tried in hyponatremic elderly individuals with diagnostic uncertainty, ${ }^{23}$ challenging to distinguish between hyponatremia due to disorders pituitary-adrenal axis and SIADH in elderly individuals. Our patient did not respond to any one of these medications used preoperatively. However, his serum sodium normalized over postoperative $72 \mathrm{~h}$, which indicated the possible diagnosis of paraneoplastic SIADH, ruling out reset osmostat syndrome and renal salt wasting.

In conclusion, refractory hyponatremia in elderly cancer patients might be due to paraneoplastic SIADH and was corrected by surgical removal of the tumor. Although our single case cannot conclude the feasibility, anesthetic management of chronic asymptomatic yet severe hyponatremia might be expedient. Clear consensus and guidelines are lacking for accepting an urgent or expedited case despite chronic hyponatremia being a common clinical scenario in the elderly; perioperative physicians should focus on reducing the dilemma. However, we will need randomized controlled studies for the same.

\section{References}

1. Janicic N, Verbalis JG. Evaluation and management of hyperosmolality in hospitalized patients. Endocrinol Metab Clin North Am 2003;32:459-81.

2. Upadhyay A, Jaber BL, Madias NE. Epidemiology of hyponatremia. Semin Nephrol 2009;29:227-38.

3. $\mathrm{Xu} \mathrm{J}$, Chen $\mathrm{X}$, Wang $\mathrm{X}$, et al. Preoperative hyponatremia and hypocalcemia predict poor prognosis in elderly gastric cancer patients. Cancer Manag Res 2019;11:8765-80.

4. Reazaul Karim HM, Sahoo SK, Prakash A, et al. Abnormal routine preoperative test results and their perioperative anesthetic impact in patients aged 60 years and more: an observational study. Indian Anaesth Forum 2018;19:6-10.

5. Ramesh B, Pillai VS, Koshy RC, et al. Role of preoperative investigations in elderly patients undergoing oncosurgical procedures - A retrospective review audit. J Anaesthesiol Clin Pharmacol 2018;34:535-9.

6. Lee KC, Lee IO. Preoperative laboratory testing in elderly patients. Curr Opin Anaesthesiol 2021;34:409-14.

7. Verghese SC, Mahajan A, Uppal B. Chronic versus new-onset hyponatremia in geriatric patients undergoing orthopedic surgery. Int J App Basic Med Res 2019;9:37-43

8. Mannesse CK, Vondeling AM, van Marum RJ, et al. prevalence of hyponatremia on geriatric wards compared to other settings over four decades: a systematic review. Ageing Res Rev 2013;12:165-73.

9. Shapiro DS, Sonnenblick M, Galperin I, et al. Severe hyponatraemia in elderly hospitalized patients: prevalence, aetiology and outcome. Intern Med J 2010;40:574-80.

10. Maeda K, Kageyama S, Osafune T, et al. syndrome of inappropriate antidiuretic hormone secretion as a side effect of chemotherapy for testicular cancer: a case report. IJU Case Rep 2019;2:327-9.

11. Berghmans T, Paesmans M, Body JJ. A prospective study on hyponatraemia in medical cancer patients: epidemiology, aetiology and differential diagnosis. Support Care Cancer 2000;8:192-7.

12. Jeppesen AN, Jensen HK, Donskov F, et al. hyponatremia as a prognostic and predictive factor in metastatic renal cell carcinoma. Br J Cancer 2010;102:867-72.

13. Caird FI, Andrews GR, Kennedy RD. Effect of posture on blood pressure in the elderly. Br Heart J 1973;35:527-30.

14. Kleinfeld M, Casimir M, Borra S. Hyponatremia as observed in achronic disease facility. J Am Geriatr Soc 1979;27:156-61.

15. Arieff AI, Llach F, Massry SG. Neurological manifestations of morbidity of hyponatremia: correlation with brain water and electrolytes. Medicine (Baltimore) 1976;55:121-9.

16. Schrier RW. Does 'asymptomatic hyponatremia' exist? Nat Rev Nephrol 2010;6:185.

17. Renneboog B, Musch W, Vandemergel $\mathrm{X}$, et al. Mild chronic hyponatremia is associated with falls, unsteadiness, and attention deficits. Am J Med 2006;119:e71-8.

18. Renneboog B, Sattar L, Decaux G. Attention and postural balance are much more affected in older than in 
younger adults with mild or moderate chronic hyponatremia. Eur J Intern Med 2017;41:e25-6.

19. Hoorn EJ, Liam is G, Zietse R, et al. hyponatremia and bone: an emerging relationship. Nat Rev Endocrinol 2011;8:33-9.

20. Sahay M, Sahay R. Hyponatremia: a practical approach. Indian J Endocrinol Metab 2014;18:760-71.

21. Spasovski G, Vanholder R, Allolio B, et al. Clinical practice guideline on diagnosis and treatment of hyponatraemia. Nephrol Dial Transplant 2014; 29:i1-i39.

22. Liam G, Filippatos TD, Elisaf MS.
Treatment of hyponatremia: the role of lixivaptan. Expert Rev Clin Pharmacol 2014;7:431-41.

23. Takei M, Suzuki S, Sato A, et al. Five cases of severe hyponatremia in the elderly successfully treated with low doses of hydrocortisone. Geriatr Gerontol Int 2009;9:391-4. 